\title{
Synthesis and photophysical properties of ruthenocene-[60]fullerene dyads $\dagger$
}

\author{
Juan José Oviedo, ${ }^{a}$ Mohamed E. El-Khouly, ${ }^{c d}$ Pilar de la Cruz, ${ }^{a}$ Laura Pérez, ${ }^{a}$ \\ Javier Garín, ${ }^{b}$ Jesús Orduna, $^{b}$ Yasuyuki Araki, ${ }^{c}$ Fernando Langa ${ }^{* a}$ and \\ Osamu Ito $* c$
}

Received (in Montpellier, France) 6th July 2005, Accepted 24th October 2005

First published as an Advance Article on the web 11th November 2005

DOI: $10.1039 /$ b509221c

Two novel ruthenocene- $\mathrm{C}_{60}$ dyads, with a 2-pyrazoline ring or a pyrrolidine ring as a linker, have been synthesized with the aim of providing a simple model of natural photosynthesis. The photophysical properties of the two ruthenocene- $\mathrm{C}_{60}$ dyads have been investigated by steady-state absorption and fluorescence, time-resolved fluorescence and nanosecond transient measurements in polar and non-polar solvents. The charge separation takes place in the ruthenocenepyrazolino[60]fullerene more efficiently than in the ruthenocene-pyrrolidino[60]fullerene dyad. The lifetimes of the charge-separated states of the ruthenocene-pyrazolino[60]fullerene and the ruthenocene-pyrrolidino[60]fullerene dyads are $100 \mathrm{~ns}$ in $\mathrm{PhCN}$. It was found that the ruthenocene-[60]fullerenes have an ability to prolong the charge-separated states compared with those for ferrocene-[60]fullerenes.

\section{Introduction}

The importance and complexity of natural photosynthesis ${ }^{1}$ make the study of suitable simpler models of great interest. An important approach to build these models is to link covalently an electron acceptor and an electron donor. The special electrochemical ${ }^{2}$ and photophysical ${ }^{3}$ properties of fullerenes, which include absorption in the visible region and a low reorganization energy that can accelerate the photoinduced charge separation and decelerate charge recombination, ${ }^{4}$ have placed $\mathrm{C}_{60}$ and its derivatives amongst the most important organic materials for photovoltaic applications, particularly plastic solar cells. ${ }^{5}$ Numerous examples of molecular systems covalently linked between electron donors and $\mathrm{C}_{60}$ have been synthesized to date in the search for efficient photoinduced charge separation and slow charge recombination. ${ }^{6}$ A variety of donors have been attached to fullerenes ${ }^{7}$ and, among them, ferrocene has been exploited intensively ${ }^{7 e, 8}$ due to its reversible low oxidation potential.

Nevertheless, combinations of other metallocenes, such as ruthenocene, with $\mathrm{C}_{60}$ remain unexplored. Recently, we de-

\footnotetext{
${ }^{a}$ Facultad de Ciencias del Medio Ambiente, Universidad de CastillaLa Mancha, 45071 Toledo, Spain. E-mail:

Fernando.LPuente@uclm.es; Fax: +34 902204 130; Tel: 34925268843

${ }^{b}$ Departamento de Química Orgánica, ICMA, Universidad de Zaragoza-CSIC, E-50009 Zaragoza, Spain. E-mail:

jorduna@unizar.es; Fax: + 34976761 194; Tel: 34976761194

${ }^{c}$ Institute of Multidisciplinary Research for Advanced Materials,

Tohoku University, Katahira, Aoba-ku, Sendai, 980-8577, Japan.

E-mail: ito@tagen.tohoku.ac.jp; Fax: +81-22-217-5608

${ }^{d}$ Department of Chemistry, Faculty of Education, Kafr El-Sheikh,

Tanta University, Egypt. E-mail: elkhouly@tagen.tohoku.ac.jp

$\dagger$ Electronic supplementary information (ESI) available: copies of ${ }^{1} \mathrm{H}$

NMR, ${ }^{13} \mathrm{C}$ NMR and MS spectra for compounds 2, 3 and $\mathbf{4}$ and transient absorption spectra of $\mathbf{5}$ in toluene and benzonitrile. See DOI: $10.1039 / \mathrm{b} 509221 \mathrm{c}$
}

scribed the synthesis and preliminary studies on ruthenocene$\mathrm{C}_{60}$ dyads. ${ }^{9}$ The first ionization potentials (IPs) for ferrocene and ruthenocene are 6.86 and $7.45 \mathrm{eV}$, respectively. ${ }^{10,11}$ Thus, ferrocene is a stronger donor in an electron-transfer sense. In many electron-donor (D) and electron-acceptor (A) systems, however, there is a little evidence to distinguish between the donor strengths of ferrocene and ruthenocene in systems with strong electron-acceptors. Indeed, there is electrochemical evidence that ruthenocene is the stronger donor, despite the fact that it has a lower energy HOMO than ferrocene. ${ }^{12}$ The superior donating properties of ruthenocene in some D-A dyads can be attributed to the more extensive d-orbitals of ruthenium, ${ }^{13}$ which lead to increase direct or indirect spatial overlap with the acceptor. ${ }^{14}$ It seems that this difference in donor strength between ferrocene and ruthenocene is most evident when $\eta^{6}$-fulvene is a significant resonance form. These findings stimulated us to investigate in detail the electrochemical and optical properties of ruthenocene-fullerene dyads.

In the work described here, two new ruthenocene- $\mathrm{C}_{60}$ ( $\mathrm{Rc} \sim \mathrm{C}_{60}$ ) dyads $\mathbf{3}$ and $\mathbf{4}$ were synthesized with different linking bridges to the fullerene cage. In case of dyad 3, a pyrazoline ring was used whereas a pyrrolidine ring was incorporated in dyad 4. The photophysical behavior of both dyads was investigated using different photochemical techniques in polar and non-polar solvents.

\section{Results and discussion}

\section{Syntheses and characterization}

The synthetic approach to prepare the 2-pyrazolino[60]fullerene derivative 3 is based on the 1,3-dipolar cycloaddition reaction of the nitrile imine generated in situ from the corresponding hydrazone 2 . This hydrazone was prepared in $90 \%$ yield from ruthenocenecarboxaldehyde $(\mathbf{1})^{15}$ and 


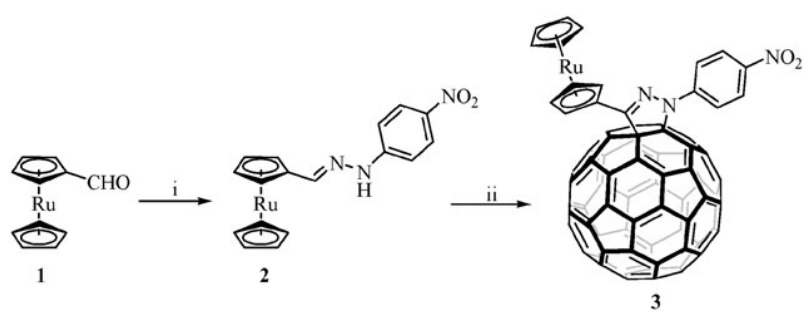

Scheme 1 (i) 4-Nitrophenylhydrazine and (ii) NBS, $\mathrm{C}_{60}$ and $\mathrm{Et}_{3} \mathrm{~N}$.

4-nitrophenylhydrazine in EtOH under reflux for 20 minutes (Scheme 1). It was necessary to modify our previously described general procedure to obtain compound $\mathbf{3}$ in a good yield. ${ }^{16,17}$ The reaction of 2 with $\mathrm{NBS}$ in $\mathrm{CHCl}_{3}$ at room temperature was followed by the addition of $\mathrm{C}_{60}$ and $\mathrm{Et}_{3} \mathrm{~N}$ in dry toluene at $40{ }^{\circ} \mathrm{C}$. The mixture was stirred for 45 minutes to give compound 3 in 16\% isolated yield after flash column chromatography (silica gel, toluene) followed by centrifugation in hexane, methanol and diethyl ether.

On the other hand, pyrrolidino[60]fullerene system 4 was prepared in $26 \%$ yield by a 1,3-dipolar cycloaddition reaction $^{18}$ between the ruthenocenecarboxaldehyde (1), $\alpha$-aminophenyl- acetic acid and $\mathrm{C}_{60}$ in chlorobenzene under microwave irradiation $^{19}$ at $210 \mathrm{~W}$ for 45 minutes in a focused microwave oven (Scheme 2). 1'-(4-Nitrophenyl)-3'-(ferrocenyl)pyrazolino [60]fullerene (5) (Chart 1) was prepared as previously described. $^{23}$

The structures of dyads 3 and $\mathbf{4}$ were confirmed by spectroscopic analysis (NMR, FT-IR and MS). The ${ }^{1} \mathrm{H}$ NMR spectra of $\mathrm{C}_{60}$ derivatives exhibited all expected signals for the organic addends. In the case of compound 3, the 4-nitrophenyl group signals were observed between 8.00 and $8.50 \mathrm{ppm}$ and the ruthenocene protons appeared as a singlet around $4.50 \mathrm{ppm}$ for the unsubstituted cyclopentadienyl ring and as two multiplets, between 4.50 and $5.50 \mathrm{ppm}$, for the $\mathrm{C}_{5} \mathrm{H}_{4}$ moiety. Similar characteristic signals for the ruthenocene moiety were also observed in the ${ }^{1} \mathrm{H}$ NMR spectrum of compound 4 , together with signals for the pyrrolidine ring, which appear as singlets at 5.91 and $5.58 \mathrm{ppm}$, and the signals for the protons of the phenyl group between 7.26 and $8.00 \mathrm{ppm}$. The ${ }^{13} \mathrm{C} \mathrm{NMR}$ spectra are also consistent with the proposed structures, with the signals from the ruthenocene fragment between 70.0 and $75.0 \mathrm{ppm}$ and those due to the corresponding $\mathrm{sp}^{2}$ carbons of the sphere between 160.0 and $134.0 \mathrm{ppm}$. In addition, the two $\mathrm{sp}^{3}$ carbon signals for the functionalized $\mathrm{C}_{60}$ cage were observed at around 89.0 and $76.0 \mathrm{ppm}$. The MALDI-MS ana-
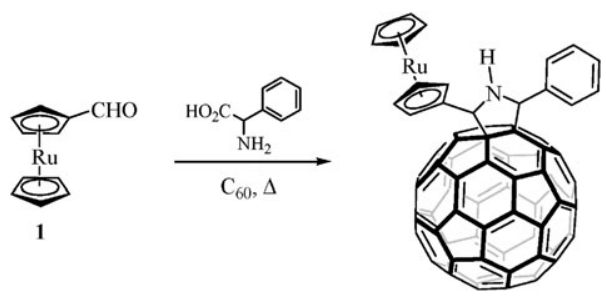

4
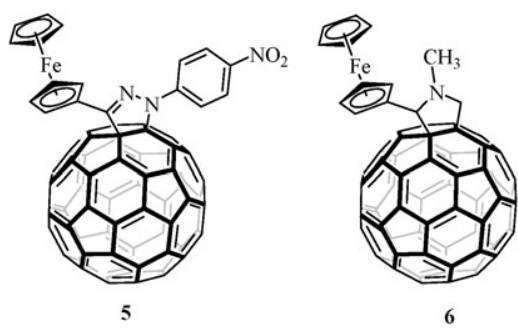

Chart 1 Reference compounds 5 and $\mathbf{6}$.

lyses for $\mathbf{3}$ and $\mathbf{4}$ revealed the molecular ion peaks to be in agreement with the calculated ones. Finally, in the UV-Vis spectra, measured in $\mathrm{CH}_{2} \mathrm{Cl}_{2}$, the characteristic absorption of $\mathrm{C}_{60}$ monoadducts was observed at around $430 \mathrm{~nm}$.

\section{Optimized structures and frontier MO's.}

Optimized geometries (B3PW91/LanL2DZ) for $\mathbf{3}$ and $\mathbf{4}$ are shown in Fig. 1. The most important structural difference arises from the fact that conjugation of the para-nitrophenyl group with the ruthenocene moiety across the pyrazoline ring in compound $\mathbf{3}$ gives rise to an almost planar arrangement, with the pyrazoline ring forming an angle of $8^{\circ}$ with the cyclopentadiene ring linked to it.

On the other hand, the lack of conjugation between the ruthenocene group and the pyrrolidine ring in compound 4 allows free rotation around the bond linking these units and the ruthenocene group is arranged away from the $\mathrm{C}_{60}$ spheroid. The distances $\left(\mathrm{R}_{\mathrm{CC}}\right)$ from the Rc center to the center of the $\mathrm{C}_{60}$ moiety were estimated to be 7.55 and $8.40 \AA$, respectively, for compounds $\mathbf{3}$ and $\mathbf{4}$.

The HOMO and LUMO of compounds $\mathbf{3}$ and $\mathbf{4}$ are depicted in Fig. 2. It can be seen that the LUMO is localized on the $\mathrm{C}_{60}$ moiety whereas the main contribution to the HOMO is from ruthenium d orbitals in $\mathbf{4}$ and the HOMO in dyad $\mathbf{3}$ spreads from ruthenocene to the para-nitrophenyl group. These orbital topologies indicate that the charge-separated state has a structure like $\mathrm{Rc}^{\bullet+} \sim \mathrm{C}_{60}{ }^{\bullet-}$, but the positive charge in $\mathbf{3}$ is also partially supported by the pyrazoline ring and the paranitrophenyl group attached to it. It should also be noted that there is a significant difference in the calculated HOMOLUMO gaps, which are $1.86 \mathrm{eV}$ and $2.30 \mathrm{eV}$ for $\mathbf{3}$ and $\mathbf{4}$, respectively.
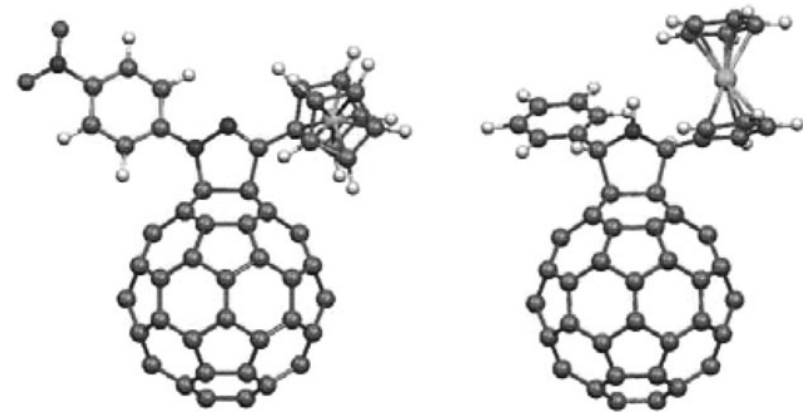

Fig. 1 Optimized geometries (B3PW91/LanL2DZ) of compounds 3 (left) and 4 (right). 


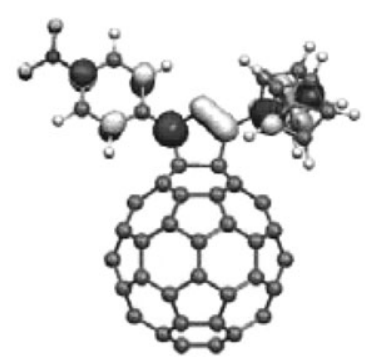

HOMO: $-6.03 \mathrm{eV}$

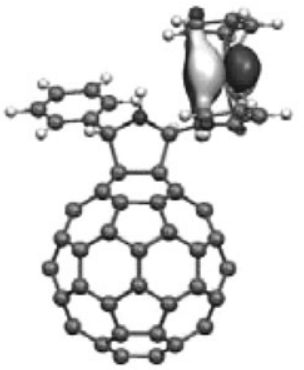

HOMO: $-5.99 \mathrm{eV}$

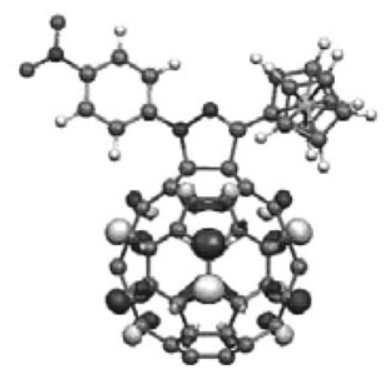

LUMO: $-4.17 \mathrm{eV}$

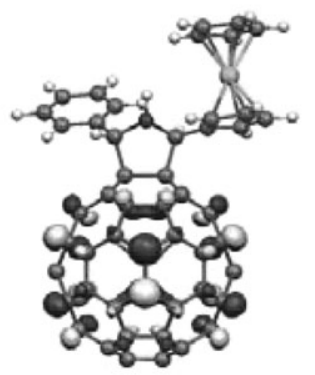

LUMO: $-3.69 \mathrm{eV}$

Fig. 2 The HOMO and LUMO of dyads 3 (top) and 4 (bottom).

\section{Electrochemistry}

Ruthenocene (Rc) based D-A systems have been much less widely studied than systems derived from ferrocene, presumably partly due to the irreversible redox chemistry of ruthenocene itself. Recently, however, it has been found that a number of substituted Rc derivatives undergo chemically (though not electrochemically) reversible two-electron oxidations. ${ }^{20}$ With the aim of estimating the energies of chargeseparated states formed by photoinduced electron transfer, the reduction and oxidation potentials of dyads $\mathbf{3}$ and $\mathbf{4}$ were determined by cyclic voltammetry $(\mathrm{CV})$ in ortho-dichlorobenzene(DCB)/acetonitrile (4:1) containing $0.1 \mathrm{M}$ tetra- $n$-butylammonium perchlorate $\left[\left(n-\mathrm{C}_{4} \mathrm{H}_{9}\right)_{4} \mathrm{NClO}_{4}\right]$ as a supporting electrolyte.

The cyclic voltammogram (CV) of compound 4 in DCB/ acetonitrile $(4: 1)$ is shown in Fig. 3. Three reversible peaks can be seen in the negative potentials down to $-2.5 \mathrm{~V} v s . \mathrm{Ag} /$ $\mathrm{Ag}^{+}$and these are attributed to the reduction potentials $\left(E_{\mathrm{red}}\right)$ of the $\mathrm{C}_{60}$ core. In the positive potential, an irreversible

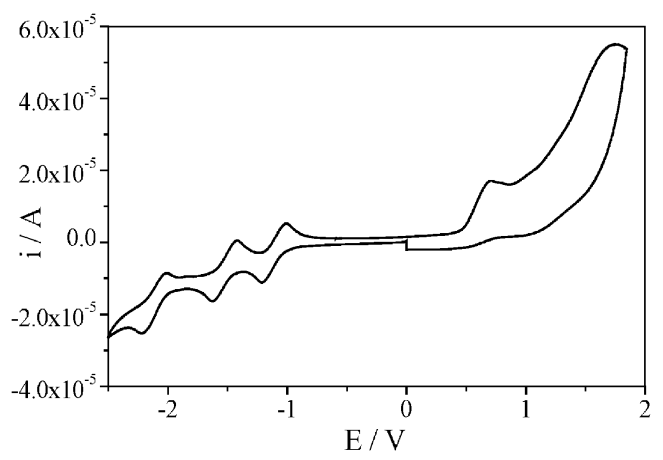

Fig. 3 Cyclic voltammogram of compound 4 in ortho-dichlorobenzene/acetonitrile $(4: 1)\left(\mathrm{V} v s . \mathrm{Ag} / \mathrm{AgNO}_{3}\right.$; scan rate was $\left.100 \mathrm{mV} \mathrm{s}^{-1}\right)$.

Table 1 Reduction potentials $(\mathrm{V})^{a}$ determined by $\mathrm{CV}$ for compounds 1-4, $\mathrm{C}_{60}$ and ruthenocene, measured in ortho-dichlorobenzene/acetonitrile $(4: 1)$

\begin{tabular}{|c|c|c|c|c|c|c|c|}
\hline & $E_{1 / 2(\mathrm{red})}^{1}$ & $E_{1 / 2(\mathrm{red})}^{2}$ & $E_{1 / 2(\text { red })}^{b}$ & $E_{1 / 2(\mathrm{red})}^{4}$ & $E_{\mathrm{ox}}^{1 b}$ & $E_{\mathrm{Ox}}^{2} b$ & $\begin{array}{l}\text { HOMO- } \\
\text { LUMO }\end{array}$ \\
\hline 1 & & & & & 0.68 & 1.17 & \\
\hline 2 & & & $-1.78^{c}$ & & 0.61 & & \\
\hline 3 & -1.01 & -1.41 & $-1.82^{c}$ & -1.96 & 0.58 & 1.42 & 1.59 \\
\hline 4 & -1.11 & -1.52 & & -2.12 & 0.71 & & 1.82 \\
\hline $\mathrm{C}_{60}$ & -0.99 & -1.40 & & -1.92 & & & \\
\hline Rc & & & & & 0.73 & & \\
\hline
\end{tabular}

${ }^{a} \mathrm{~V}$ vs. $\mathrm{Ag} / \mathrm{AgNO}_{3} ; \mathrm{GCE}$ as working electrode; $0.1 \mathrm{M}\left(n-\mathrm{C}_{4} \mathrm{H}_{9}\right)_{4}$ $\mathrm{NClO}_{4}$; scan rate was $100 \mathrm{mV} \mathrm{s}{ }^{-1} .{ }^{b}$ Irreversible. ${ }^{c}$ Assigned to the para-nitrophenyl group.

potential is observed at $0.71 \mathrm{~V} v s . \mathrm{Ag} / \mathrm{Ag}^{+}$and this corresponds to the oxidation potential $\left(E_{\mathrm{ox}}\right)$ of the Rc moiety. A similar cyclic voltammogram was obtained for $\mathbf{3}$, but a new non-reversible reduction wave at $-1.82 \mathrm{~V}$, assigned to the para-nitrophenyl moiety, also appeared. It can be seen that the $E_{\text {ox }}$ value for 3 is less positive by $0.13 \mathrm{~V}$ than that of $\mathbf{4}$, indicating the better electron-donor capability of the Rc connected to the pyrazoline ring. On the other hand, the $E_{\text {red }}$ value of $\mathbf{3}$ is less negative than that of $\mathbf{4}$ by $0.10 \mathrm{~V}$, indicating that the $\mathrm{C}_{60}$ moiety with the pyrazoline ring (3) is more electron-negative than that with pyrrolidine ring (4) as reported previously. ${ }^{17}$ The data obtained are summarized in Table 1 together with comparison data for $\mathrm{C}_{60}$, ruthenocene, formylruthenocene (1) and hydrazone $\mathbf{2}$.

The experimental $\mathrm{HOMO}_{(\mathrm{Rc})}-\mathrm{LUMO}_{(\mathrm{C} 60)}$ gap, determined as the difference between $E_{\text {red }}$ and $E_{\mathrm{ox}}$, is significantly lower for 2-pyrazoline-based dyad $3(1.59 \mathrm{eV})$ than that for pyrrolidine derivative $4(1.82 \mathrm{eV})$ according to theoretical calculations. This difference suggests an easier photoinduced electron transfer in $\mathbf{3}$ than in $\mathbf{4}$.

From the first $E_{\mathrm{ox}}$ and $E_{\text {red }}$ values, the free-energies $\left(\Delta G_{\mathrm{RIP}}\right)$ of the radical ion-pairs of $\mathrm{Rc}^{\bullet+} \sim \mathrm{C}_{60}{ }^{\bullet-}$ were calculated using the Rehm-Weller equation (eqn (1)). ${ }^{21}$

$$
\Delta G_{\mathrm{RIP}}=E_{\mathrm{ox}}(\mathrm{Rc})-E_{\mathrm{red}}\left(\mathrm{C}_{60}\right)-\Delta G_{\mathrm{S}}
$$

Here, $\Delta G_{\mathrm{S}}$ refers to the static energy calculated according to eqn (2): ${ }^{21}$

$$
\Delta G_{\mathrm{S}}=e^{2} /\left(4 \pi \varepsilon_{0} \varepsilon_{\mathrm{R}} \mathrm{R}_{\mathrm{D}-\mathrm{A}}\right)
$$

Here, the terms $e, \varepsilon_{0}$, and $\varepsilon_{\mathrm{R}}$ refer to elementary charge, vacuum permittivity and static dielectric constant of the solvent used for rate measurements and redox potential

Table 2 Free-energy changes for the charge-separation process $\left(\Delta G_{\mathrm{CS}}\right)^{a}$ and charge-recombination $\left(\Delta G_{\mathrm{RIP}}\right)$ in benzonitrile $(\mathrm{PhCN})$ and toluene

\begin{tabular}{lllcc}
\hline Compound & Solvent & $\begin{array}{l}\Delta G_{\mathrm{RIP}} / \\
\mathrm{eV}\end{array}$ & $\begin{array}{l}\Delta G_{\mathrm{CS}} / \mathrm{eV} \\
\text { via }{ }^{1} \mathrm{C}_{60} *\end{array}$ & $\begin{array}{l}\Delta G_{\mathrm{CS}} / \mathrm{eV} \\
\text { via }^{3} \mathrm{C}_{60} *\end{array}$ \\
\hline $\mathbf{3}$ & PhCN & -1.38 & -0.37 & -0.15 \\
& Toluene & -1.97 & 0.22 & 0.44 \\
& PhCN & -1.61 & -0.14 & 0.08 \\
& Toluene & -2.20 & 0.45 & 0.67 \\
& &
\end{tabular}

${ }^{a} E_{00}=1.75 \mathrm{eV}$ for ${ }^{1} \mathrm{C}_{60}{ }^{*}$, and $E_{00}=1.50 \mathrm{eV}$ for ${ }^{3} \mathrm{C}_{60} *$. 
measurements, respectively. Based on $\Delta G_{\text {RIP }}$ and excited energy $\left(E_{00}\right)$ values, the free-energy changes of the chargeseparation process $\left(\Delta G_{\mathrm{CS}}\right)$ were calculated (eqn (3)) as listed in Table 2.

From these $\Delta G_{\mathrm{CS}}$ values, the charge-separation process of $\mathbf{3}$ and 4 via the excited singlet state of $\mathrm{C}_{60}\left({ }^{1} \mathrm{C}_{60} *\right)$ is sufficiently exothermic in benzonitrile. In toluene, the CS process seems to be slightly endothermic, taking into consideration that the Weller model in toluene is likely an oversimplification, and the exact values quoted above are probably not completely reliable. The charge-separation process via the excited triplet state of $\mathrm{C}_{60}\left({ }^{3} \mathrm{C}_{60} *\right)$ is exothermic for 3 in $\mathrm{PhCN}$, but endothermic in toluene.

$$
-\Delta G_{\mathrm{CS}}=\Delta G_{\mathrm{CR}}-E_{00}
$$

For dyad 4 , the $\Delta G_{\mathrm{CS}}$ values of ${ }^{3} \mathrm{C}_{60} *$ are endothermic in $\mathrm{PhCN}$ and toluene.

\section{Steady-state absorption spectra}

The absorption spectra of dyads $\mathbf{3}$ and $\mathbf{4}$ measured in $\mathrm{PhCN}$ are shown in Fig. 4. The absorption bands above $400 \mathrm{~nm}$ are attributed to the $\mathrm{C}_{60}$ moiety. The absorption band of the Rc moiety is expected to appear at wavelengths below $400 \mathrm{~nm}$, but the intensity of this band is weak compared with the huge absorption band of $\mathrm{C}_{60}$ in this region. The absorption intensities of compound $\mathbf{3}$ are slightly stronger than those of $\mathbf{4}$ in the $380-480 \mathrm{~nm}$ region. The absorption spectrum of pyrrolidino[60]fullerene dyad 4 is essentially a linear combination of the absorption spectra of the reference compounds, ruthenocene and $N$-methylpyrrolidino[60]fullerene, suggesting that there is no significant electronic interaction between the ruthenocene and fullerene in the ground state. On the other hand, the absorption band of compound 3 in the $380-480 \mathrm{~nm}$ region suggests interaction between the $\mathrm{C}_{60}$ moiety and Rc through
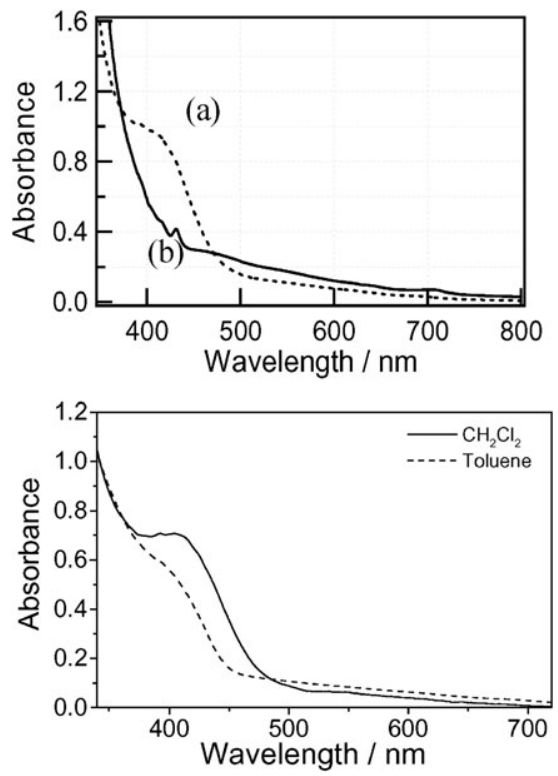

Fig. 4 (top) Steady-state absorption spectra of compounds 3 (a, --) and 4 (b, -) in PhCN. (bottom) UV-vis spectra of $\mathbf{3}$ in dichloromethane (-) and toluene (--). The concentrations were kept at $2 \times 10^{-5} \mathrm{M}$. the pyrazolino group. The absorption band at around $400 \mathrm{~nm}$ for dyad 3 changes with solvent polarity, as depicted in Fig. $4 \mathrm{~b}$. It can be seen that the broad band at around $400 \mathrm{~nm}$ decreases in toluene, suggesting a polar electronic interaction between ruthenocene and $\mathrm{C}_{60}$ in the ground state. ${ }^{8 a, 22}$ Similar behaviour has been observed in the analogous ferrocene-2pyrazolino[60]fullerene dyad $\mathbf{5}^{23}$

\section{Steady-state fluorescence spectra}

The photochemical behaviour of dyads $\mathbf{3}$ and $\mathbf{4}$ was investigated using steady-state fluorescence measurements. The steady-state fluorescence spectra of compounds $\mathbf{3}$ and $\mathbf{4}$ are shown in Fig. 5. The spectra were obtained using a detector consisting of a special photomultiplier tube with relatively high sensitivity in the wavelength region above $600 \mathrm{~nm}$. The measurements were carried out in different solvents ( $\mathrm{PhCN}, \mathrm{DCB}$ and toluene) by applying an excitation wavelength of $400 \mathrm{~nm}$, which exclusively excites the $\mathrm{C}_{60}$ moiety. The emission observed in the range $700-760 \mathrm{~nm}$ for 4 in toluene is a typical fluorescence of the pyrrolidino- $\mathrm{C}_{60}$ moiety. In the case of $\mathbf{3}$ in toluene, a new fluorescence was observed at $653 \mathrm{~nm}$ in addition to the peak at $720 \mathrm{~nm}$.

The emission peak at $653 \mathrm{~nm}$ is typical of a pyrazolino- $\mathrm{C}_{60}$ moiety attached to the Rc moiety. In polar solvents, these emission intensities were almost completely quenched compared with those in toluene. These observations suggest efficient quenching of the singlet excited state of the $\mathrm{C}_{60}$ moiety by the appended Rc moieties in polar solvents. The close spatial separation between the fullerene and the Rc group is expected to lead to efficient deactivation of the fullerene singlet excited state. In toluene the $720 \mathrm{~nm}$ emission of $\mathbf{3}$ was weak compared with that for $\mathbf{4}$, suggesting a weak quenching process for $\mathbf{3}$ even in toluene.
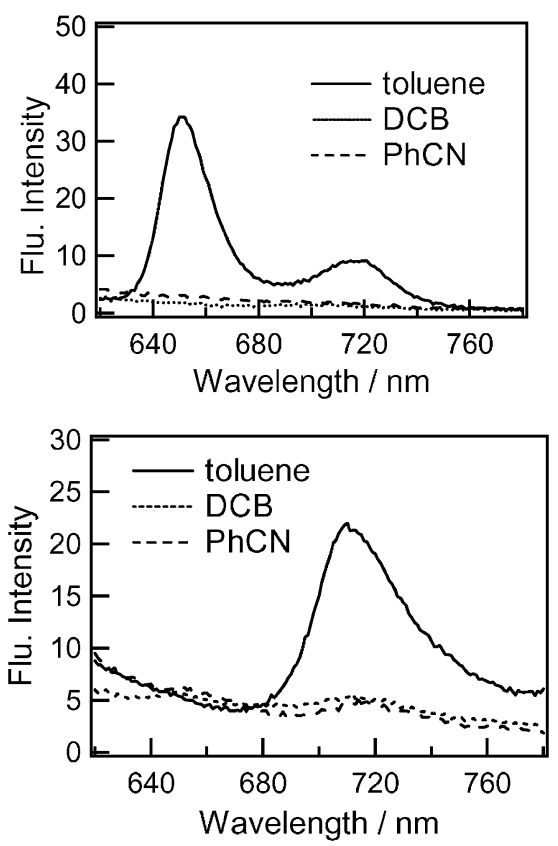

Fig. 5 Steady-state fluorescence spectra of (top) dyad $\mathbf{3}$ and (bottom) dyad 4 in different organic solvents; $\lambda_{\mathrm{ex}}=400 \mathrm{~nm}$. 

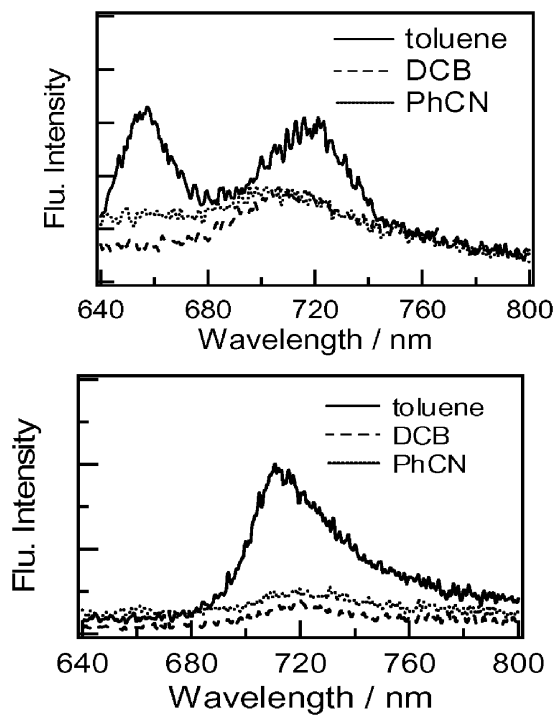

Fig. 6 Time resolved spectra of (top) dyad 3 and (bottom) dyad $\mathbf{4}$ in different solvents; $\lambda_{\mathrm{ex}}=400 \mathrm{~nm}$.

\section{Time-resolved fluorescence spectra and fluorescence lifetimes}

The time-resolved fluorescence spectral features of dyads 3 and 4 in polar solvents (DCB and $\mathrm{PhCN}$ ) and a non-polar solvent (toluene) are shown in Fig. 6; the emission spectra are depicted in the time range of $0.1-0.6 \mathrm{~ns}$.

In these experiments a streak-scope was used as the detector. The observed emission spectra in toluene are similar to those of the steady-state measurements, supporting the reliability of our measurements for these weak emissions. For compound 3 in DCB, the emission band at $653 \mathrm{~nm}$ disappeared but the remaining 700-720 nm emission is consistent with the steadystate measurement thus providing evidence of efficient quenching in polar solvents.
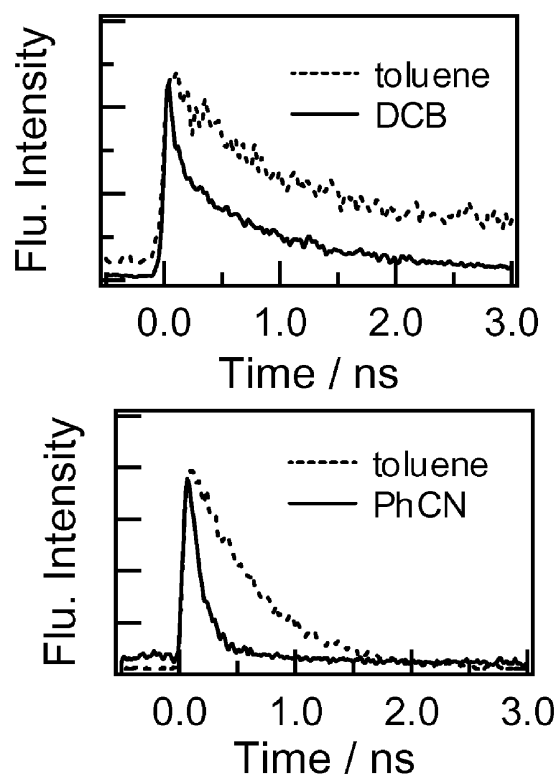

Fig. 7 Fluorescence decay profiles monitored at $720 \mathrm{~nm}$ of (top) 3 and (bottom) $4 ; \lambda_{\mathrm{ex}}=400 \mathrm{~nm}$.
Table 3 Fluorescence lifetimes $\left(\tau_{\mathrm{f}}\right)$ of ${ }^{1} \mathrm{C}_{60}{ }^{*}$, rate constants $\left(k_{\mathrm{CS}}\right)$ and quantum yield $\left(\Phi_{\mathrm{CS}}\right)$ for charge-separation via ${ }^{1} \mathrm{C}_{60} *$ for $\mathbf{3}$ and $\mathbf{4}$ in toluene, DCB, and PhCN

\begin{tabular}{lllrr}
\hline Compound & Solvent & $\tau_{\mathrm{FS}} / \mathrm{ps}$ & \multicolumn{1}{c}{$k_{\mathrm{CS}} / \mathrm{s}^{-1}$} & \multicolumn{1}{c}{$\Phi_{\mathrm{CS}}$} \\
\hline $\mathbf{3}$ & PhCN & Very fast & $>1.0 \times 10^{10}$ & $>0.90$ \\
& DCB & 200(65\%) 1550(35\%) & $4.1 \times 10^{9}$ & 0.83 \\
& Toluene & $750(70 \%) 2000(40 \%)$ & $5.6 \times 10^{8}$ & 0.42 \\
$\mathbf{4}$ & & & $5.8 \times 10^{9}$ & 0.87 \\
& PhCN & 150 & $1.6 \times 10^{9}$ & 0.66 \\
& DCB & 400 & $5.9 \times 10^{8}$ & 0.41 \\
\hline
\end{tabular}

The fluorescence decay-time profiles at $700 \mathrm{~nm}$ for dyads 3 and $\mathbf{4}$ are shown in Fig. 7. The fluorescence time profile of the reference $\mathrm{C}_{60}$ exhibited a single exponential decay with a lifetime $\left(\tau_{\mathrm{f} 0}\right)$ of $1.3 \mathrm{~ns}$. The attachment of donor moieties introduces a new quenching pathway for the lowest excited singlet state of the $\mathrm{C}_{60}$ moieties in dyads $\mathbf{3}$ and $\mathbf{4}$. In polar and non-polar solvents, the recorded fluorescence lifetimes monitored at $720 \mathrm{~nm}$ for both dyads are shorter than the $\left(\tau_{\mathrm{f} 0}\right)$ value, suggesting that the fluorescence quenching occurs from the ${ }^{1} \mathrm{C}_{60} *$ moiety. The fluorescence decay time profile can be fitted with two exponential components for $\mathbf{3}$, from which two lifetimes can be evaluated (see Table 3 ).

The short lifetimes $\left(\tau_{\mathrm{f}}\right)$ are in the 200 and 420 ps range in DCB and toluene, respectively. In PhCN, the fast part of the process was too fast to record. For compound 4, the lifetimes were evaluated by curve-fitting with a single exponential and gave values in the range $150-620$ ps. The fluorescence lifetimes became shorter on increasing the solvent polarity, suggesting that the quenching process is due to the charge separation from the donor moieties to the $\mathrm{C}_{60}$ moiety to yield the chargeseparated (CS) state. The rate constants for charge separation $\left(k_{\mathrm{CS}}\right)$ were calculated using the eqn $(4)$ :

$$
k_{\mathrm{CS}}=1 / \tau_{\mathrm{f}}-1 / \tau_{\mathrm{f} 0}
$$

where $\tau_{\mathrm{fo}}$ and $\tau_{\mathrm{f}}$ are the lifetimes of the reference and investigated compound, respectively. The quantum yields $\left(\Phi_{\mathrm{CS}}\right)$ for the generation of the CS state via ${ }^{1} \mathrm{C}_{60}$ * were calculated using the eqn (5):

$$
\Phi_{\mathrm{CS}}=\left(1 / \tau_{\mathrm{f}}-1 / \tau_{\mathrm{fo}}\right) / 1 / \tau_{\mathrm{f}}
$$

The charge-separation rate constant $\left(k_{\mathrm{CS}}\right)$ and quantum yield $\left(\Phi_{\mathrm{CS}}\right)$ were evaluated as shown in Table 3 . The higher values of both $k_{\mathrm{CS}}$ and $\Phi_{\mathrm{CS}}$ for $\mathbf{3}$ in comparison to those of $\mathbf{4}$ suggest better charge-separation ability in $\mathbf{3}$ than $\mathbf{4}$. In each compound, the $k_{\mathrm{CS}}$ and $\Phi_{\mathrm{CS}}$ values increase with solvent polarity, indicating that the charge-separated process belongs to the normal region of the Marcus parabola. ${ }^{24}$ It is worth noting that in toluene the charge separation takes place for both $\mathbf{3}$ and 4. This observation is consistent with the fact that nitrogen atom near the $\mathrm{C}_{60}$ moiety acts as a strong electron-donor in the non-polar solvent. ${ }^{25}$ Compared with the ferrocene $(\mathrm{Fc})$ derivatives with similar structures $\mathbf{5}$ and $\mathbf{6}$, the $k_{\mathrm{CS}}$ values for the Rc derivatives are smaller than those of the Fc derivatives (5: $k_{\mathrm{CS}}=9.9 \times 10^{9} \mathrm{~s}^{-1}$ in toluene (supporting information; Fig. $\mathrm{S} 1 \dagger$ ) and 6: $2.2 \times 10^{11} \mathrm{~s}^{-1}$ in $\left.\mathrm{PhCN}\right)^{8}$ by one order and two order for $\mathbf{3}$ and $\mathbf{4}$, respectively, reflecting weaker donor ability of the Rc moiety than the Fc moiety, as revealed by the higher $E_{\mathrm{Ox}}$ of the Rc moiety than that of the Fc moiety. ${ }^{8}$ 

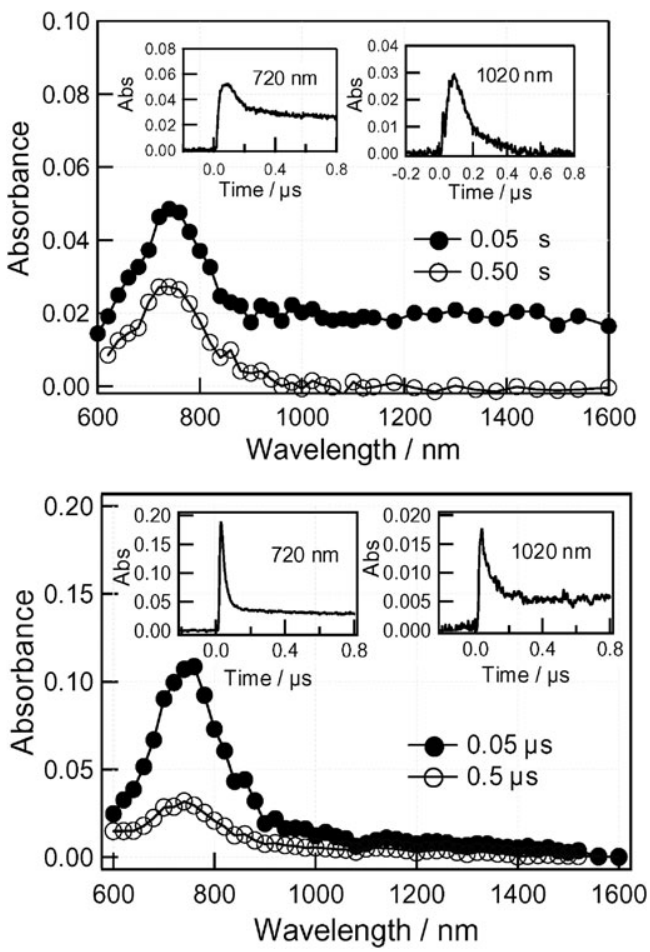

Fig. 8 Transient absorption spectra of compound $3(0.1 \mathrm{mM})$ obtained by 355 laser light photolysis in Ar-saturated (top) PhCN and (bottom) toluene.

\section{Transient absorption measurements}

The nanosecond transient spectra of 3 in $\mathrm{PhCN}$ by $355 \mathrm{~nm}$ laser light photolysis (Fig. 8, top), where $\mathrm{C}_{60}$ can be predominantly excited, were measured. Immediately after laser excitation (spectrum at $50 \mathrm{~ns}$ ), the transient absorption peak appeared at $720 \mathrm{~nm}$ with a broad absorption in the 1000$1600 \mathrm{~nm}$ region. At $500 \mathrm{~ns}$, the broad absorption in the nearIR region disappeared and the absorption at $720 \mathrm{~nm}$ remained. This remaining absorption band was assigned to the triplet state of $\mathrm{C}_{60}\left({ }^{3} \mathrm{C}_{60} *\right)$. The rapidly decaying absorption can be ascribed to the radical ion pair $\mathrm{Rc}^{\bullet+} \sim \mathrm{C}_{60}{ }^{-}$. In general, the $\mathrm{C}_{60}{ }^{\bullet-}$ moiety shows a clear absorption peak at $1000 \mathrm{~nm}$; however, only a broad absorption was observed in the case of compound 3. One possible explanation for this is overlap of the absorption due to $\mathrm{Rc}^{\bullet}{ }^{+}$.

The time profiles in the inset in Fig. 8 (top) show that the decay processes in the near-IR region give a decay rate constant of $k_{(1020 \mathrm{~nm})}=9.6 \times 10^{6} \mathrm{~s}^{-1}$, which is attributed to the charge-recombination rate constant $\left(k_{\mathrm{CR}}\right)$ of $\mathrm{Rc}^{\bullet+} \sim \mathrm{C}_{60}{ }^{\bullet-}$. The inverse of the $k_{\mathrm{CR}}$ value gave the lifetime $\left(\tau_{\mathrm{RIP}}\right)$ of $\mathrm{Rc}^{\bullet+} \sim \mathrm{C}_{60}{ }^{--}$to be $100 \mathrm{~ns}$ in $\mathrm{PhCN}$ at room temperature. The decay-time profile at $720 \mathrm{~nm}$ shows dual decays; the initial decay rate is in good agreement with the $k_{\mathrm{CR}}$ value, suggesting the absorption of $\mathrm{Rc}^{\bullet+} \sim \mathrm{C}_{60}{ }^{\bullet-}$ is overlapping in this region. The difference transient absorption spectrum obtained subtracting the transient spectrum at $500 \mathrm{~ns}$ from that at $50 \mathrm{~ns}$ is all attributed to $\mathrm{Rc}^{\bullet+} \sim \mathrm{C}_{60}{ }^{\bullet-}$. The slow decay at $720 \mathrm{~nm}$ can be attributed to the lifetime of $\mathrm{Rc} \sim{ }^{3} \mathrm{C}_{60} *$. In toluene (Fig. 8 (bottom)) the predominant absorption peak appeared at $720 \mathrm{~nm}$ and this is due to the ${ }^{3} \mathrm{C}_{60} *$ moiety. The

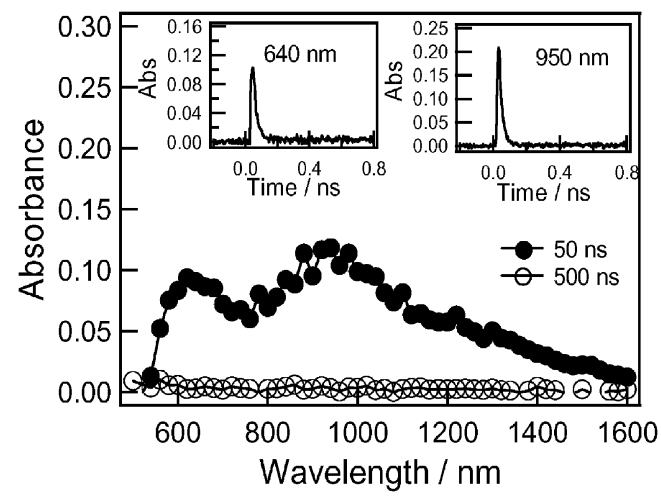

Fig. 9 Transient absorption spectra of compound 2 (0.1 mM) obtained by 532 laser light photolysis in $\mathrm{Ar}$-saturated $\mathrm{PhCN}$.

rapid decay at $720 \mathrm{~nm}$ can be attributed mainly to rapid decay of the ${ }^{3} \mathrm{C}_{60} *$ moiety due to the heavy atom effect.

The transient absorption spectra of $\mathbf{2}$ observed by exciting the Rc moiety with $532 \mathrm{~nm}$ light in PhCN are shown in Fig. 9, which exhibited the broad absorption spectra with maxima at 640, 950 and $1200 \mathrm{~nm}$ in the $50 \mathrm{~ns}$ spectrum. These bands might be attributed to the radical ion-pairs $\left(\mathrm{Rc}^{\bullet+} \sim \mathrm{PhNO}_{2}{ }^{\bullet-}\right)$. The lifetime of the radical-pairs was evaluated as $20 \mathrm{~ns}$ which is shorter than that of $\mathbf{3}$.

In the case of $\mathbf{5}$, the transient absorption spectra (supporting information; Fig. S2 $\dagger$ ) exhibited only the weak absorption band of triplet $\mathrm{C}_{60}$ at $720 \mathrm{~nm}$ without evidence of the forming of radical ion-pairs. This suggests that the charge recombination after efficient charge separation is fast, because of stronger donor ability of the Fc moiety. On the contrary, the chargerecombination of the $\mathrm{Rc}$ derivatives is slow, because the charge-recombination process may belong to the Marcus inverted region ${ }^{24}$ due to sufficiently negative $\Delta G_{\text {RIP }}$ values in Table 2 .

The transient absorption spectra of compound $\mathbf{4}$ in $\mathrm{PhCN}$ are shown in Fig. 10 (top). In the spectrum at 50 ns, the strong absorption appearing at $720 \mathrm{~nm}$ is due to the ${ }^{3} \mathrm{C}_{60} *$ moiety. In comparison to dyad $\mathbf{3}$, the absorbance of $\mathbf{4}$ at $720 \mathrm{~nm}$ is stronger by a factor of 10 , suggesting the predominant generation of the ${ }^{3} \mathrm{C}_{60} *$ moiety. In the near-IR region, the broad absorption tail seems to be extended, although the relative intensity of the near-IR band of compound $\mathbf{4}$ is weak compared with that at $720 \mathrm{~nm}$. The rapid-decay in the near-IR band can be attributed to $\mathrm{Rc}^{\bullet+} \sim \mathrm{C}_{60}{ }^{\bullet-}$. On the other hand, the band at $720 \mathrm{~nm}$ can be attributed to the ${ }^{3} \mathrm{C}_{60} *$ moiety, although the decay was very fast, probably due to the heavy atom effect of Rc.

In the case of $\mathbf{4}$ in toluene, similar transient absorption spectra were observed and these are shown in Fig. 10 (bottom). Although the absorption shape is quite similar to that in $\mathrm{PhCN}$, the time-profiles were quite different. The decay rates at $720 \mathrm{~nm}$ and the near-IR region were quite slow, which suggests that these bands are due to the ${ }^{3} \mathrm{C}_{60} *$ moiety. Indeed, the decay was accelerated on addition of $\mathrm{O}_{2}$ and this provides further evidence for this assignment. From the fluorescence quenching, the charge-separation takes place via the ${ }^{1} \mathrm{C}_{60} *$ moiety; however, the fast charge-recombination produces the ${ }^{3} \mathrm{C}_{60} *$ moiety. 

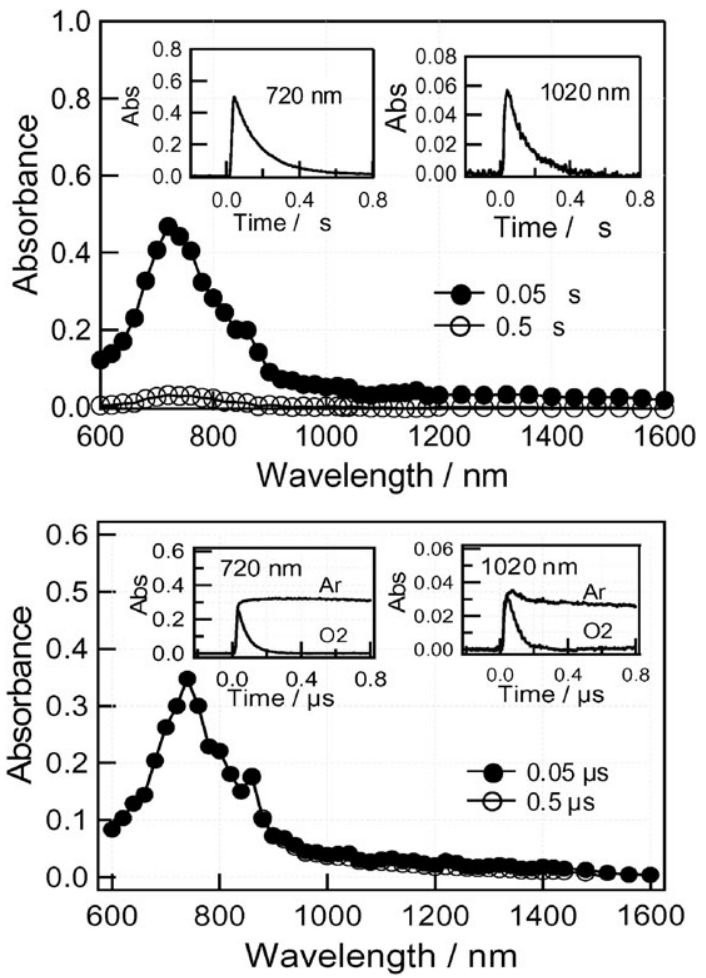

Fig. 10 Transient absorption spectra of compound $4(0.1 \mathrm{mM})$ obtained by 355 laser light photolysis in Ar-saturated (top) PhCN and (bottom) toluene.

In Table 4 , the charge-recombination rate constants $\left(k_{\mathrm{CR}}\right)$ of $\mathrm{Rc}^{\bullet+} \sim \mathrm{C}_{60}{ }^{\bullet-}$ evaluated from the decay at $1020 \mathrm{~nm}$ are summarized. The $k_{\mathrm{CR}}$ value in $\mathrm{PhCN}$ is larger than that in toluene for 3. Lifetimes of the radical ion-pairs are as long as $100 \mathrm{~ns}$ in $\mathrm{PhCN}$ for both 3 and 4. Compared with $\mathbf{6}\left(k_{\mathrm{CR}}=\right.$ $4.5 \times 10^{9} \mathrm{~s}^{-1}$ in $\left.\mathrm{PhCN}\right),{ }^{8}$ the $k_{\mathrm{CR}}$ values for the Rc derivatives are quite smaller, probably because of the high hole trapping ability of the Rc moiety.

\section{Energy diagram}

The energy diagram after photo-excitation is depicted in Fig. 11 , in which the lowest excited state data were evaluated from the $0-0$ band of the longest wavelength of the transition. The energy level of $\mathrm{Rc}^{\bullet+} \sim \mathrm{C}_{60}{ }^{--}$in $\mathrm{PhCN}$ is slightly lower than those in $\mathrm{DCB} /$ acetonitrile in Table 2. The negative $\Delta G_{\mathrm{CS}}$ values in polar solvents render charge separation from both ${ }^{1} \mathrm{Rc}^{*}$ and ${ }^{1} \mathrm{C}_{60}{ }^{*}$, suggesting possible charge-separation. However, the energy level of $\mathrm{Rc}^{\bullet}{ }^{+} \sim \mathrm{C}_{60}{ }^{\bullet-}$ in toluene is higher than

Table 4 Charge recombination rate constant $\left(k_{\mathrm{CR}}\right)$ and lifetimes $\left(\tau_{\mathrm{RIP}}\right)$ of $\mathrm{Rc}^{\bullet+} \sim \mathrm{C}_{60}$

\begin{tabular}{|c|c|c|c|}
\hline Compound & Solvent & $k_{\mathrm{CR}} / \mathrm{s}^{-1}$ & $\tau_{\mathrm{RIP}} / \mathrm{ns}$ \\
\hline 3 & $\begin{array}{l}\text { PhCN } \\
\text { Toluene }\end{array}$ & $\underset{b}{9.6} \times 10^{6}$ & $\begin{array}{r}100 \\
-b\end{array}$ \\
\hline 4 & $\begin{array}{l}\text { PhCN } \\
\text { Toluene }\end{array}$ & $\left.\frac{(9.1}{b} \times 10^{6}\right)^{a}$ & $\underbrace{(100)^{a}}_{b}$ \\
\hline
\end{tabular}

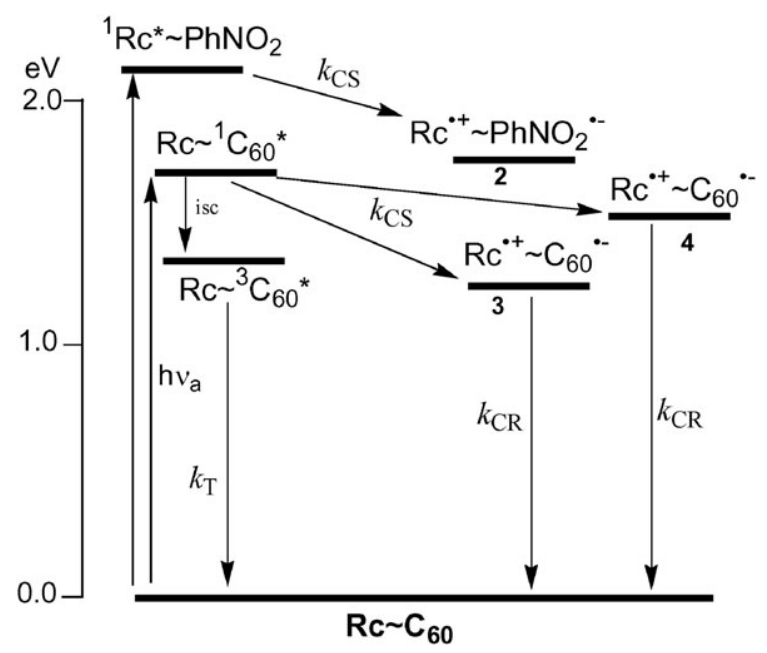

Fig. 11 Energy diagram of $\mathbf{3}$ and $\mathbf{4}$ in benzonitrile.

that in PhCN, although the values in toluene may be associated with considerable error.

In the case of compound $\mathbf{3}$ in $\mathrm{PhCN}$, the charge-separation process takes place mainly via ${ }^{1} \mathrm{C}_{60} *$ moiety generating $\mathrm{Rc}^{\bullet+} \sim \mathrm{C}_{60}{ }^{\bullet-}$. Minor contribution of forming $\mathrm{Rc}^{\bullet+} \sim \mathrm{C}_{60}{ }^{\bullet-}$ may arise via the electron migration (transfer) from $\mathrm{Rc}^{\bullet+} \sim \mathrm{PhNO}_{2}{ }^{--}$to $\mathrm{C}_{60}$ to yield the final $\mathrm{Rc}^{\bullet+} \sim \mathrm{C}_{60}{ }^{\bullet-}$ in $\mathrm{PhCN}$. As in Table 1, the energy level of $\mathrm{Rc}^{\bullet+} \sim \mathrm{PhNO}_{2}{ }^{--}$is higher than that of $\mathrm{Rc}^{\bullet+} \sim \mathrm{C}_{60}{ }^{\bullet-}$, because the reduction potential of $\mathrm{PhNO}_{2}$ group was more negative than that of $\mathrm{C}_{60}$ moiety. The charge-recombination of ion-pair, $\mathrm{Rc}^{\bullet+} \sim \mathrm{C}_{60}{ }^{\bullet-}$ may produce the ground states. In toluene, the charge-separation process of $\mathbf{3}$ is minor, because of the endothermic process; therefore, intersystem crossing takes place competitively with the charge-separation process. The chargerecombination of ion-pair, $\mathrm{Rc}^{\bullet+} \sim \mathrm{C}_{60}{ }^{\bullet-}$ may produce the ${ }^{3} \mathrm{C}_{60} *$ in addition to the direct production of the ground states.

In the case of dyad 4 in $\mathrm{PhCN}$, the charge-separation process via the ${ }^{1} \mathrm{C}_{60} *$ moiety is a minor process. Similar results were observed for $6 .{ }^{8}$ The considerable ${ }^{3} \mathrm{C}_{60} *$ moiety is produced via intersystem crossing and via the charge-recombination process since the charge-separated state is higher than ${ }^{3} \mathrm{C}_{60} *$. For the generation of ${ }^{3} \mathrm{C}_{60} *$ moiety in toluene, the contribution of the intersystem crossing increases compared with that of the charge-recombination process, if any.

\section{Conclusions}

In summary, we have synthesized two new donor-acceptor dyads based on ruthenocene as the electron donor and 2pyrazolino[60]fullerene and pyrrolidino[60]fullerene as electron acceptors. The electrochemical and photophysical properties of the two dyads have been studied. Cyclic voltammetry measurements show a lower $\mathrm{HOMO}_{\mathrm{Rc}}-\mathrm{LUMO}_{\mathrm{C} 60}$ gap in the 2-pyrazolino[60]fullerene dyad (3) than in the pyrrolidino[60]fullerene (4) system and this order is supported by theoretical calculations at the B3PW91/LanL2DZ level. The photophysical properties of the ruthenocene- $\mathrm{C}_{60}$ dyads were investigated by measuring the time-resolved fluorescence and nanosecond 
transient spectra in polar and non-polar solvents. A different type of behaviour was observed in each of these two dyads. The photoinduced charge separation takes place efficiently in 2-pyrazolino[60]fullerene-ruthenocene, whereas the charge-separation efficiency becomes quite low in pyrrolidino[60]fullerene-ruthenocene. This finding reveals that the pyrazoline ring mediates charge-separation due to the higher electron-donating ability of the pyrazoline ring compared with that of that pyrrolidine ring. Compared with the corresponding ferrocene$\mathrm{C}_{60}$ derivatives, the slower charge-separation and slower charge-recombination were confirmed for ruthenocene- $\mathrm{C}_{60}$ derivatives.

\section{Experimental}

\section{General remarks}

All cycloaddition reactions were performed under argon. $\mathrm{C}_{60}$ was purchased from MER Corporation (Tucson, AZ). TLC using Merck silica gel $60-\mathrm{F}_{254}$ was used to monitor cycloaddition reactions. ${ }^{1} \mathrm{H}$ NMR and ${ }^{13} \mathrm{C}$ NMR spectra were recorded on Varian Mercury 200 and Varian Inova 500 spectrometers. FT-IR spectra were recorded on a Nicolet Impact 410 spectrophotometer using $\mathrm{KBr}$ disks. MALDI-TOF mass spectra were obtained on a Bruker ReflexIII spectrometer. Elemental analyses were performed on a Perkin-Elmer 2400 CHNS/O Series II analyzer.

The UV/Vis spectra were obtained using a Jasco model V570 DS spectrophotometer or a Shimatzu spectrophotometer. Steady-state fluorescence spectra were measured on a Shimadzu RF-5300 PC spectrofluorophotometer equipped with a photomultiplier tube with high sensitivity in the 700-800 nm region.

Cyclic voltammetry measurements were carried out on an Autolab PGSTAT 30 potentiostat using a BAS MF-2062 Ag/ $0.01 \mathrm{M} \mathrm{AgNO}_{3}, 0.1 \mathrm{M}\left(n-\mathrm{C}_{4} \mathrm{H}_{9}\right)_{4} \mathrm{ClO}_{4}$ in acetonitrile reference electrode, an auxiliary electrode consisting of a $\mathrm{Pt}$ wire, and a Metrohm 6.1247.000 conventional glassy carbon electrode (3 $\mathrm{mm}$ o.d.) as a working electrode directly immersed in the solution. A $10 \mathrm{~mL}$ electrochemical cell from BAS, Model VC-2, was also used. The reference potential was shifted by $290 \mathrm{mV}$ towards a more negative potential compared with the $\mathrm{Ag} / \mathrm{AgCl}$ scale. $E_{1 / 2}$ values were taken as the average of the anodic and cathodic peak potentials. Scan rate: $100 \mathrm{mV} \mathrm{s}^{-1}$.

The picosecond time-resolved fluorescence spectra were measured by a single-photon counting method using a second harmonic generation (SHG, $410 \mathrm{~nm}$ ) Ti:sapphire laser (Spectra-Physica, Tsunami 3950-L2S, $1.5 \mathrm{ps}$ fwhm) and a streakscope (Hamamatsu Photonics, C43334-01) equipped with a polychromator (Action Research, SpectraPro 150) as an excitation source and a detector, respectively. Lifetimes were evaluated with software attached to the equipment.

The nanosecond transient absorption measurements in the near-IR region were measured by means of laser-flash photolysis; $532 \mathrm{~nm}$ light from a Nd:YAG laser (Spectra-Physics and Quanta-Ray GCR-130, $6 \mathrm{~ns}$ fwhm) was used as an excitation source. For transient absorption spectra in the near-IR region (600-1200 nm), monitoring light from a pulsed Xe-lamp was detected with Ge-avalanche photodiode module (Hamamatsu
Photonics, B2834). For spectra in the visible region (400-800 nm), a Si-PIN photodiode (Hamamatsu Photonics, S1722-02) was used as a detector. All the samples were placed in a quartz cell $(1 \times 1 \mathrm{~cm})$ and were deaerated by bubbling Ar through the solution for $15 \mathrm{~min}$.

The computational calculations were performed by ab initio B3LYP/3-21G(*) methods with the GAUSSIAN 03 software package on high-speed computers. The images of the frontier orbitals were generated from Gauss View-03 software.

\section{Synthesis}

Ruthenocenecarboxaldehyde 4-nitrophenylhydrazone (2). A solution of $\mathbf{1}^{15}$ (63 g, $\left.0.24 \mathrm{mmol}\right)$, 4-nitrophenylhydrazine (37 $\mathrm{g}, 0.24 \mathrm{mmol}$ ) and two drops of acetic acid in $15 \mathrm{~mL}$ of ethanol was heated under reflux for $20 \mathrm{~min}$. The mixture was cooled to room temperature, filtered and the solid was recrystallized from ethanol. The product was obtained as a red solid in $90 \%$ yield $(85 \mathrm{mg})\left(\mathrm{mp} 207-208{ }^{\circ} \mathrm{C}\right)$. IR(KBr) $\nu / \mathrm{cm}^{-1} 3271,1543$, 1474, 1286, 1167, 808. ${ }^{1} \mathrm{H}$ NMR (200 MHz, $\left.\mathrm{CDCl}_{3}\right) \delta / \mathrm{ppm}$ $8.14(\mathrm{~d}, J=9.5 \mathrm{~Hz}, 2 \mathrm{H}), 7.69(\mathrm{bs}, 1 \mathrm{H}), 7.51(\mathrm{~s}, 1 \mathrm{H}), 6.98(\mathrm{~d}$, $J=9.5 \mathrm{~Hz}, 2 \mathrm{H}), 4.99(\mathrm{~m}, 2 \mathrm{H}), 4.70(\mathrm{~m}, 2 \mathrm{H}), 4.59(\mathrm{~s}, 5 \mathrm{H}) .{ }^{13} \mathrm{C}$ NMR (50 MHz, DMSO) $\delta /$ ppm 150.9, 142.1, 138.1, 126.8, 111.3, 84.8, 72.3, 71.9, 70.0. Anal. calcd. for $\mathrm{C}_{17} \mathrm{H}_{15} \mathrm{~N}_{3} \mathrm{O}_{2} \mathrm{Ru}$ : C, 51.77; H, 3.83; N, 10.65\%. Found: C, 51.15; H, 3.64; N, $10.65 \%$; UV-Vis $\lambda_{\text {max }}\left(\mathrm{CH}_{2} \mathrm{Cl}_{2}\right) / \mathrm{nm}(\log \varepsilon) 394$ (4.0), 235 (5.3).

$1^{\prime}$-(4-Nitrophenyl)-3'-(ruthenocenyl)pyrazolino $\left[4^{\prime}, 5^{\prime}: 1,2\right]$ [60] fullerene (3). An Ar-blanketed solution of NBS (53 mg, 0.03 $\mathrm{mmol}$ ) and hydrazone 2 (24 mg, $0.07 \mathrm{mmol})$ in dry $\mathrm{CHCl}_{3}(20$ $\mathrm{mL}$ ) was stirred at room temperature for $30 \mathrm{~min}$ under Ar. The solvent was removed in vacuo, and a solution of $\mathrm{C}_{60}(50 \mathrm{mg}$, $0.07 \mathrm{mmol}$ ) and $\mathrm{NEt}_{3}(7 \mathrm{mg}, 0.07 \mathrm{mmol})$ in dry toluene (50 $\mathrm{mL}$ ) was added to the solid. The solution was stirred for 45 min at $40{ }^{\circ} \mathrm{C}$. The solvent was removed under reduced pressure. The resulting solid was purified by silica gel flash chromatography using toluene as the eluent. Centrifugation with methanol and diethyl ether was used to further purify the solid. Compound 3 was obtained in $16 \%$ yield (12 mg). $\operatorname{IR}(\mathrm{KBr}) \nu / \mathrm{cm}^{-1} 1585,1493,1320,1274,1105,999,837,526$. ${ }^{1} \mathrm{H}$ NMR $\left(500 \mathrm{MHz}, \mathrm{CDCl}_{3}\right) \delta / \mathrm{ppm} 8.30(\mathrm{~d}, J=9.8 \mathrm{~Hz}, 2 \mathrm{H})$, $8.20(\mathrm{~d}, J=9.8 \mathrm{~Hz}, 2 \mathrm{H}), 5.52(\mathrm{~m}, 2 \mathrm{H}), 4.83(\mathrm{~m}, 2 \mathrm{H}), 4.47(\mathrm{~s}$,

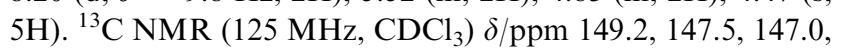
$146.2,146.1,145.9,145.8,145.7,145.5,145.3,145.1,145.0$, $144.9,144.4,144.1,143.9,143.0,142.9,142.8,142.7,142.3$, $142.1,142.0,141.8,141.78,141.70,139.7,139.2,137.7,136.8$, 134.6, 131.6, 131.3, 128.1, 125.0, 118.6, 114.6, 114.0, 112.7, 91.4, 81.3, 72.9, 71.9, 71.4. $\mathrm{MS} m / z: 1113.0(\mathrm{M}+1), 720\left(\mathrm{C}_{60}\right)$; UV-Vis $\lambda_{\max }\left(\mathrm{CH}_{2} \mathrm{Cl}_{2}\right) / \mathrm{nm}(\log \varepsilon) 430$ (4.5), 392 (4.5), 320 (4.8), 255 (5.3).

$5^{\prime}$-(Phenyl)-2'-ruthenocenylpyrrolidino $\left[3^{\prime}, 4^{\prime}: 1,2\right][60]$ fullerene (4). A solution of $\mathbf{1}(57 \mathrm{mg}, 0.22 \mathrm{mmol}), \alpha$-aminophenylacetic acid $(83 \mathrm{mg}, 0.55 \mathrm{mmol})$ and $\mathrm{C}_{60}(80 \mathrm{mg}, 0.11 \mathrm{mmol})$ in chlorobenzene $(50 \mathrm{~mL})$ was irradiated at $210 \mathrm{~W}$ for $45 \mathrm{~min}$ in a focused microwave oven. The solvent was removed under reduced pressure. The resulting solid was purified by silica gel flash chromatography using toluene as the eluent. Centrifugation with methanol and pentane was used to further purify the 
solid. Compound 4 was obtained in $26 \%$ yield $(31 \mathrm{mg}$ ). $\operatorname{IR}(\mathrm{KBr}) \nu / \mathrm{cm}^{-1} 3417,2916,2328,1643,1427,1103,702 .{ }^{1} \mathrm{H}$ NMR $\left(500 \mathrm{MHz}, \mathrm{CDCl}_{3}\right) \delta / \mathrm{ppm} 7.95(\mathrm{~d}, J=7.02 \mathrm{~Hz}, 2 \mathrm{H})$, $7.42(\mathrm{~m}, 3 \mathrm{H}), 5.91(\mathrm{~s}, 1 \mathrm{H}), 5.58(\mathrm{~s}, 1 \mathrm{H}), 5.35(\mathrm{~s}, 1 \mathrm{H}), 5.00(\mathrm{~s}$, $1 \mathrm{H}), 4.71(\mathrm{~s}, 5 \mathrm{H}), 4.62(\mathrm{~s}, 1 \mathrm{H}) ;{ }^{13} \mathrm{C} \mathrm{NMR}\left(125 \mathrm{MHz}, \mathrm{CDCl}_{3} /\right.$ $\left.\mathrm{CS}_{2}\right) \delta / \mathrm{ppm} 154.7,154.6,153.4,147.6,147.5,147.4,147.3$, $147.1,146.8,146.5,146.4,146.3,146.27,146.1,146.0,145.7$, $145.5,145.4,145.0,144.6,143.4,142.9,142.8,142.5,142.4$, $142.3,142.2,140.17,139.9,139.6,138.3,129.0,128.9,128.8$, 89.6, 74.7, 71.7, 71.295, 71.2, 71.18, 70.5. MS $m / z$ : 1066.1 $(\mathrm{M}-1)$; UV-Vis $\left(\mathrm{CH}_{2} \mathrm{Cl}_{2}\right) \mathrm{UV}-\mathrm{V}$ is $\lambda_{\max }\left(\mathrm{CH}_{2} \mathrm{Cl}_{2}\right) / \mathrm{nm}(\log \varepsilon)$ 430 (4.0), 326 (5.0), 310 (5.0), 257 (5.3).

$1^{\prime}$-(4-Nitrophenyl)-3'-(ferrocenyl)pyrazolino $\left[4^{\prime}, 5^{\prime}: 1,2\right] \quad[60]$ fullerene (5). This compound was prepared as previously described. ${ }^{23}$

\section{Acknowledgements}

Financial support for this work was provided by a grant from the Ministerio de Educación y Ciencia of Spain, FEDER funds (Project CTQ2004-00364/BQU) and the Junta de Comunidades de Castilla-La Mancha (Project PAI-02-023). This research was partially supported by a Grant-in-Aid for the COE project, Giant Molecules and Complex Systems, 2002. This work was also supported by a Grant-in-Aid for Scientific Research on Priority Area (417) from the Ministry of Education, Culture, Sports, Science, and Technology of Japanese Government.

\section{References}

1 (a) The Photosynthetic Reaction Center, ed. J. Deisenhofer and J. R. Norris, Academic Press, New York, 1993; (b) T. Brixner, J. Stenger, H. M. Vaswani, R. E. Blankenship and G. Fleming, Nature, 2005, 434, 625-628.

2 J. Chlistunoff, D. Cliffer and A. J. Bard, in Handbook of Organic Conductive Molecules and Polymers, ed. H. S. Nalwa, John Wiley \& Sons, New York, 1997, vol. 1, ch. 7.

3 Optical and Electronic Properties of Fullerenes and Fullerene-based Materials, ed. J. Shinar, Z. V. Vardeny and Z. H. Kafafi, Marcel Dekker Inc., New York, 2000.

4 P. J. Bracher and D. Schuster, in Fullerenes: from synthesis to optoelectronic properties, ed. D. Guldi and N. Martín, Kluwer Academic Publishers, Dordrecht, 2002.

5 (a) C. J. Brabec, N. S. Sariciftci and J. C. Hummelen, Adv. Funct. Mater., 2001, 11, 15-26; (b) F. Wudl, J. Mater. Chem., 2002, 12, 1959-1963; (c) J.-F. Nierengarten, Sol. Energy Mater. Sol. Cells, 2004, 83, 187-199.

6 (a) D. M. Guldi, Chem. Soc. Rev., 2002, 31, 22-36; (b) D. Gust, T. A. Moore and A. L. Moore, Acc. Chem. Res., 2001, 34, 40-48.

7 For recent reviews see: $(a)$ N. Martín, L. Sánchez, B. Illescas and I. Pérez, Chem. Rev., 1998, 98, 2527-2547; (b) M. Prato and M. Maggini, Acc. Chem. Res., 1998, 31, 519-526; (c) F. Diederich and M. Gómez-López, Chem. Soc. Rev., 1999, 28, 263-277; (d) H. Imahori and Y. Sakata, Eur. J. Org. Chem., 1999, 2445-2457; (e) H. Imahori, K. Tamaki, H. Yamada, K. Yamada, Y. Sakata, Y. Nishimura, I. Yamazaki, M. Fujitsuka and O. Ito, Carbon, 2000,
38, 1599-1605; ( $f$ ) D. I. Schuster, Carbon, 2000, 38, 1607-1614; $(g)$ J. L. Segura and N. Martín, Chem. Soc. Rev., 2000, 29, 13-25; (h) D. M. Guldi, Chem. Soc. Rev., 2002, 31, 22-36; (i) J.-F. Nierengarten, N. Armaroli, G. Accorsi, Y. Rio and J.-F. Eckert, Chem.Eur. J., 2003, 9, 36-41.

8 (a) D. M. Guldi, M. Maggini, G. Scorrano and M. Prato, J. Am. Chem. Soc., 1997, 119, 974-980; (b) H. Imahori, H. Yamada, Y. Nishimura, I. Yamazaki and Y. Sakata, J. Phys. Chem. B, 2000, 104, 2099-2018; (c) F. Langa, P. de la Cruz, E. Espildora, A. Gonzalez-Cortes, A. de la Hoz and V. Lopez-Arza, J. Org. Chem., 2000, 65, 8675-8684; (d) H. Imahori, H. Norieda, H. Yamada, Y. Nishimura, I. Yamazaki, Y. Sakata and S. Fukuzumi, J. Am. Chem. Soc., 2001, 123, 100-110; (e) F. D. D'Souza, M. E. Zandler, P. M. Smith, G. R. Deviprasad, F. M. Arkady and O. Ito, J. Phys. Chem. A, 2002, 106, 649-656; (f) M. E. Zandler, P. M. Smith, M. Fujitsuka, O. Ito and F. D. D'Souza, J. Org. Chem., 2002, 67, 9122-9129; (g) S. Campidelli, E. Vazquez, D. Milic, M. Prato, J. Barbera, D. M. Guldi, M. Marcaccio, D. Paolucci, F. Paolucci and R. Deschenaux, J. Mater. Chem., 2004, 14, 1266-1272.

9 J. J. Oviedo, P. de la Cruz, J. Garín, J. Orduna and F. Langa, Tetrahedron Lett., 2005, 46, 4781-4784.

10 S. Evans, M. L. H. Green, B. Jewitt, A. F. Orchard and C. F. Pygall, J. Chem. Soc., Faraday Trans. 2, 1972, 68, 1847-1865.

11 C. Cauletti, J. C. Green, M. R. Kelly, J. Robbins and J. C. Smart, J. Electron Spectrosc. Relat. Phenom., 1980, 19, 327-353.

12 S. Barlow, L. M. Henling, M. W. Day, W. P. Schaefer, J. C. Green, T. Hascall and S. R. Marder, J. Am. Chem. Soc., 2002, 124, 62856296.

13 S. Barlow and S. R. Marder, Chem. Commun., 2000, 1555-1562.

14 S. Barlow, H. E. Bunting, C. Ringham, J. C. Green, G. U. Bublitz, S. G. Boxer, J. W. Perry and S. R. Marder, J. Am. Chem. Soc., 1999, 121, 3715-3727.

15 R. Sanders and U. T. Mueller-Westerhoff, J. Organomet. Chem., 1996, 512, 219-224.

16 P. de la Cruz, A. Díaz-Ortiz, J. J. García, M. J. Gómez-Escalonilla, A. de la Hoz and F. Langa, Tetrahedron Lett., 1999, 40, 15871590.

17 (a) F. Langa, P. de la Cruz, E. Espíldora, A. de la Hoz, J. L. Bourdelande, L. Sánchez and N. Martín, J. Org. Chem., 2001, 66, 5033-5041; (b) J. L. Delgado, P. de la Cruz, V. Lopez-Arza, F. Langa, D. B. Kimball, M. M. Haley, Y. Araki and O. Ito, J. Org. Chem., 2004, 69, 2661-2668.

18 M. Prato and M. Maggini, Acc. Chem. Res., 1998, 31, 519-526.

19 Microwave irradiation has proven to be a useful source of energy in fullerene chemistry. See: A. de la Hoz, A. Díaz-Ortiz and F. Langa, in Microwaves in Organic Synthesis, ed. A. Loupy, WileyVCH, New York, 2002, pp. 295-343.

20 (a) M. Sato, A. Kudo, Y. Kawata and H. Saitoh, Chem. Commun., 1996, 25-26; (b) M. Sato, Y. Kawata, A. Kudo, A. Iwai, H. Saitoh and S. Ochiai, J. Chem. Soc., Dalton Trans., 1998, 13, 2215-2224.

21 A. Z. Weller, Z. Phys. Chem., Neue Folge, 1982, 133, 93-98.

22 (a) Y. Nakamura, T. Minowa, S. Tobita, H. Shizuka and J. Nishimura, J. Chem. Soc., Perkin Trans. 2, 1995, 2351-2357; (b) J. Llacay, J. Veciana, J. V. Gancedo, J. L. Bourdelande, R. G. Moreno and C. Rovira, J. Org. Chem., 1998, 63, 5201-5210; (c) R. Fong II, D. I. Schuster and S. R. Wilson, Org. Lett., 1999, 1, 729-732; (d) T. Ohno, K. Moriwaki and T. Minaya, J. Org. Chem., 2001, 66, 3397-3401.

23 E. Espíldora, J. L. Delgado, P. de la Cruz, A. de la Hoz, V. LópezArza and F. Langa, Tetrahedron, 2002, 58, 5821-5826.

24 R. A. Marcus, J. Chem. Phys., 1956, 24, 966-978.

25 (a) A. Ouchi, R. Hatsuda, B. Z. S. Awen, M. Sakuragi, R. Ogura, T. Ishii, Y. Araki and O. Ito, J. Am. Chem. Soc., 2002, 124, 13364-13365; (b) A. Ouchi, B. Z. S. Awen, R. Hatsuda, R. Ogura, T. Ishii, Y. Araki and O. Ito, J. Phys. Chem. A, 2004, 108, 9584-9592. 